\title{
Design and Development of Heavy Drone for Fire Fighting Operation
}

\author{
Vimalkumar. R, Karan Kumar Shaw \\ Department of Aerospace Engineering \\ SRM Institute of Science and Technology, Kattankulathur, Tamil Nadu, India
}

\begin{abstract}
Fire Accidents can cause serious injury and damages to the personnel and personal property. General Fire accidents occur often unexpectedly and sudden. Times of India published that, with 27,027 deaths, every fifth Fire related deaths in the world in 2017 took place in India. Around 9 million Fire incidents and 1.2 Lakh deaths were recorded across the globe that year. Thirty five Indians die in Fire accident daily, says the National Crime Records Bureau (NCRB) based on the 12,748 lives in 2018. When the Fire service responders arrive on a Fire scene, it is very difficult for them to predict the situation inside the building or any closed area subjected to Fire, so Drone can be a solution for the Firefighters to take decisions about where to concentrate resources and how to approach and enter the scene. A Drone mounted Fire Extinguisher Balls, Thermal camera, water in storage tank with a pump to pressurize the water, can be employed in an Emergency situation where human intervention is not possible. The Fire Balls dropped into the Flame, where it activates and spread a dry powder Fire Extinguisher agent. These Fire extinguisher puts off $\mathrm{A}, \mathrm{B}$ or $\mathrm{C}$ class fires. The Thermal Imaging camera can be used to sense the presence of Fire, it also indicates the presence of people who were trapped in the buildings and they can be found easily even in the presence of Smoke, where the Fire fighters cannot be seen through their Naked eyes.
\end{abstract}

Keywords-Drone; Fire Extinguisher ball; Thermal Imaging camera.

\section{INTRODUCTION}

Drones are basically flying unmanned robot that can be remotely controlled or made to fly autonomously through software-controlled flight plans in their embedded systems, working in conjunction with onboard sensors and GPS. The drones need to become smart and quick-witted in order to optimize industrial processes, maximize their utility and can be widely established in future factories. This technology offers various applications not only in the field of aerial surveillance and monitoring but also firefighting operations. On $13^{\text {th }}$ Dec 2017, a drone was being sued by the Los Angeles Fire Department in their effort to combat the tremendous wildfires that have been ravaging the city and surrounding areas. Later, it was also used to determine the property damage that has been done by the Creek Fire near Sylmar and the Skirball Fire in the Bel Air and Sepulveda Pass, LA.

Fire departments are seeing a greater prospect of using drones during structure fires and rescue missions. In case of structure fire, when the fire fighters first arrive at the scene, the drone can be deployed to carefully monitor the scene, before the firefighter personals are put in harm's way. When equipped with a thermal camera, the drone can reveal where the hotspots are, and also have the ability to see through smoke and in low light conditions. These infrared cameras can then allow operators to recon crew members and conditions, improving efficiency and safety. The drone can also be equipped with a spotlight to help firefighters in dark or low light conditions. After the smoke has cleared, the drones can also be used for critical evaluation of damage, whether it be from a fire or other natural disaster. Drones allow firefighters to quickly and effectively scout out dangerous fires, observe and monitor a large blaze in the forests. This project aims to develop one such drone capable of performing both surveillance and firefighting operations.

\section{LITERATURE SURVEY}

One of the foremost preliminary steps for proceeding with any research paper is through a detailed survey of various journals relation to the selected topic. Herewith mentioned some of the research papers that were studied:

Burchan et al. (2019) [1] demonstrated the use of Drone assisted wildfire fighting using fire extinguishing balls as a supplement to traditional firefighting methods. The proposed system was a hexacopter with a payload weighing $15 \mathrm{~kg}$ and balls of weight $0.5 \mathrm{~kg}$ each. It consists of scouting unmanned aircraft systems (UAS) to detect spot fires and evaluating the risk of wildfire approach to the building. It also sends the relative data of the firefighting UAS to help them to control the situation. However, these balls were not effective for class A \& B fires.

Abdulla Al-Kaff et al. (2019) [2] developed autonomous UAV for the critical applications of forest fire surveillance. Algorithms implemented into the device to perform surveillance tasks within a specific area, to perform autonomous take-off/landing, trajectory planning and fire monitoring. This design is equipped with thermal cameras, temperature sensors and communication modules to provide information about the fire and reporting to the Emergency Response Team (ERT).

Manuj et al. (2019) [3] proposed the use of semiautonomous drones for firefighting operations rather than putting the life of firefighter at risk. The paper provides information about improvement on the existing hexacopter to obtain stable flight, gather and store Global Positioning System (GPS) data and perform auto- landing. The system was fitted with a fire extinguisher and any such mechanism for firefighting operations. Two successive models were made and tested and results found have positive outcomes in favour of research.

Abinesh. D. V et al. (2017) [4] designed quadcopter for the purpose of exploring the areas hit by fires. The author compared different configurations of drone and finally selected the quad with arm length of $220 \mathrm{~mm}$, owing to its 
intuitive simplicity in its manufacturing and cost effectiveness. The propeller used is $10 \times 4$ inches with the idea of improving stability. The materials of the propeller are chosen keeping in mind the temperature, the drone has to undergo while it is close to the fire.

Dr. Ronald T. et al. (2018) [5] discussed the concept and issues related to the unmanned aerial systems in the fire service. Emphasis is placed on airworthiness of the drone, command and control of the drones and crash avoidance. Recommendations include continued field testing on UASs, surveying fire chiefs to access opinions on UAS implementation. And coordination between the Federal Aviation administration (FAA) and fire chiefs in regulation development on UAS technology use in the fire service.

\section{DESIGN AND WORKING OF THE DRONE}

The Drone is Designed to have Octocopter Configuration, only then the required amount of Thrust will be produced by the rotors having small propellers. If Quadcopter or Hexacopter configurations were used then each of the propeller size has to be increased to produce thrust as same as thrust produced in Octocopter Configuration. The Main Frame is Designed as $\mathrm{H}$ - shaped due to which there is enough space to mount the payloads.

\section{A. Payload}

\section{1) FIRE EXTINGUISHER BALL}

Fireball is based on revolutionary technology that provides far more advanced solutions than portable fire extinguishers. The limitations and problems associated with conventional methods of extinction (maintenance, training, etc.) are at the origin of its development. It is easy to use and provides permanent protection as it self-activates in the presence of a flame without human intervention. The Diameter of the Ball is $15.2 \mathrm{~cm}$ and its weight are about $1.5 \mathrm{Kg}$. This Ball gets activated within 3-10 seconds in contact with the Flame.

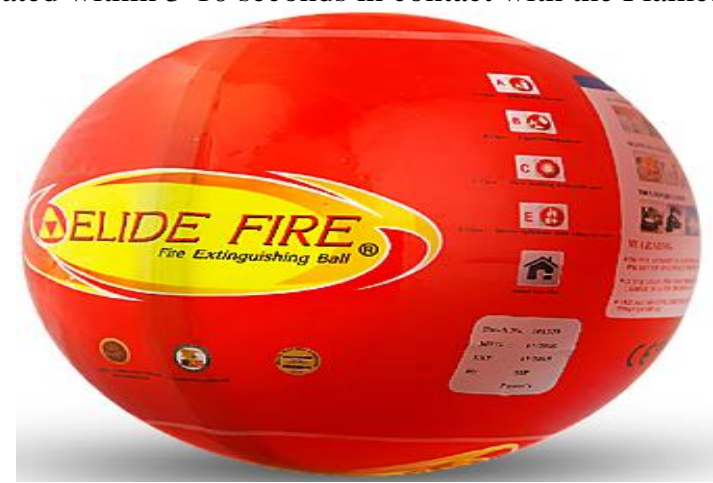

Fig 1. Fire Extinguishing Ball

\section{2) Thermal Imaging Camera}

The camera DJI Zenmuse XT, provides high-sensitivity about 50 milli Kelvin(mK), thermal imaging at 640/30 Frames Per Second (FPS) or 336/30 FPS. This sensitivity provides accurate temperature measurements ideal for analytics and telemetry. Stabilized and controlled by a custom DJI gimbal, it provides smooth, clear imagery and 360 degrees of seamless rotational movement.

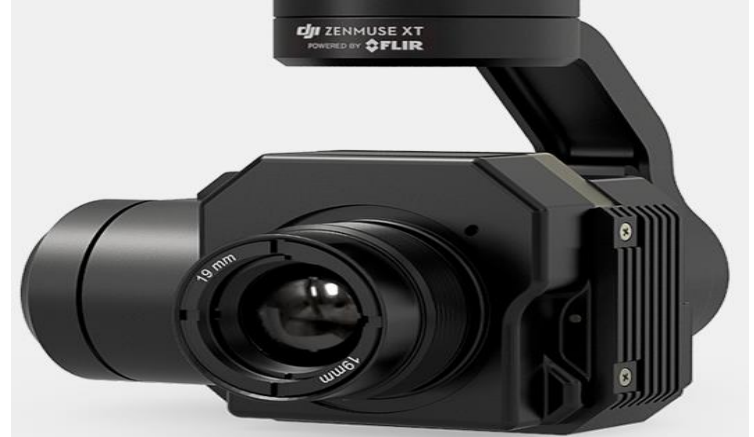

Fig 2. Thermal Imaging camera

3) Li-Po Battery to power the Camera

The battery that can be used is a six cell Li-Po battery of $1200 \mathrm{mAh} 15 \mathrm{c}$ current capacity and $22.2 \mathrm{~V}$.

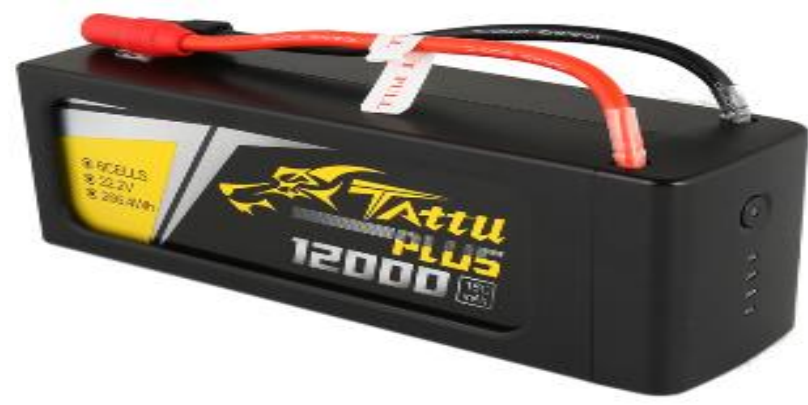

Fig 3. Li-po Battery

\section{4) Powerful LED Lights}

Light supply is required in the Dark regions and it also helps to obtain bright and clear images through the camera. The Lights system that can be mounted on the Drone is two Lume Cube 1.0 waterproof LED Lights. This light system can be adjustable via 10 manual brightness settings through Bluetooth Wireless Control or simultaneously with iPhone and Android Devices via Lume-X App. Batteries are included within the system, it can provide Light for 2 hours at $50 \%$ intensity with full battery charge.

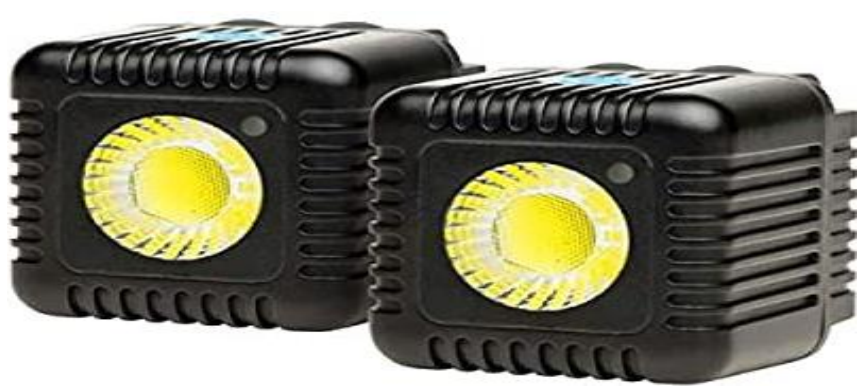

Fig 4. LED lights

\section{5) Water Storage Tank}

The water tank is made up of plastic and it has a capacity of 5 Litre mounted on the Drone, the tank has slanting bottom so that the stagnation of water can be avoided. 


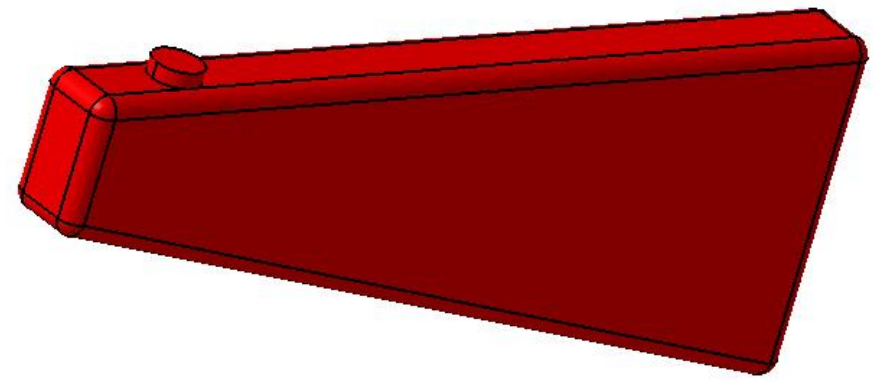

Fig 5. Water storage Tank

\section{6) Brushless Water Pump}

The water pump that can be mounted on the drone is WA3510.This pump provides pressure about $0.85 \mathrm{MPA}$ and Flow rate $5.8 \mathrm{~L} / \mathrm{min}$. It works with $24 \mathrm{~V}$ supply and has maximum current consumption $5 \mathrm{~A}$.

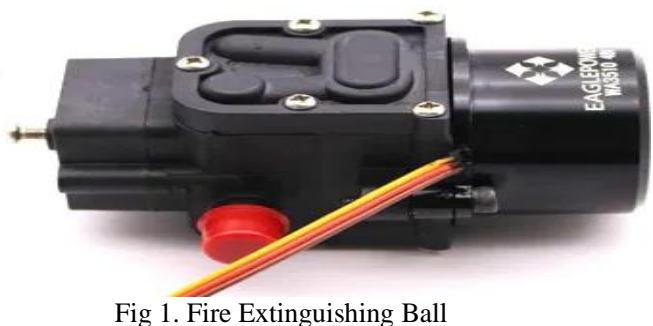

7) Total weight of payload

\begin{tabular}{|c|c|}
\hline \multicolumn{2}{|c|}{ TABLE I. Payload Data } \\
\hline PARTS & WEIGHT IN (Grams) \\
\hline Fire Extinguisher Ball (2 NO'S) & 3000 \\
\hline Camera & 300 \\
\hline Li-Po battery & 670 \\
\hline LED lights (2 NO'S) & 800 \\
\hline 5 Litre water + water tank & 5300 \\
\hline Pump & 300 \\
\hline TOTAL & $\mathbf{1 0 , 3 7 0}$ \\
\hline
\end{tabular}

B. Construction

At each free end of the arm, a motor will be fixed and propelled will be mechanically coupled to the motor. For all four motors the output side of an ESC will be connected and the input side of the ESC will be connected to the flight controller. The other input of the ESC will be connected to the power distribution board where the power supply is provided by the Li-Po battery. In a similar fashion all the other ESC's, motors and propellers are connected. A receiver will be connected to the Flight controller to receive signals from the transmitter. The Thermal imaging camera is mounted with a separate Li-Po battery power supply. The Fire Extinguisher Balls are mounted with a shell-like structure. The pump's input is connected to the storage tank and the output is connected to the pipe. The landing frame of height $400 \mathrm{~mm}$ is connected to the main frame so that the Fire Extinguisher Ball shells and the water storage tank will be safe and it will not touch the ground. The Light systems are also mounted on the front side of the Drone.

\section{Working}

The signals will be transmitted from Transmitter and it will be received by the Receiver in the drone. From the receiver the signal goes to the Flight controller where the signal will be processed with accelerometer and gyroscope sensors. The processed signal will be sent to the ESC, which allows the specific amount to the motor based on the signal it receives. The propellers are mechanically coupled to the motors so that they rotate and produce thrust. A servo motor controlled through a Transmitter, is used to open the shell in which the Fire Extinguisher Ball is kept inside. Flow rate of the Pump can also be controlled through the Transmitter.

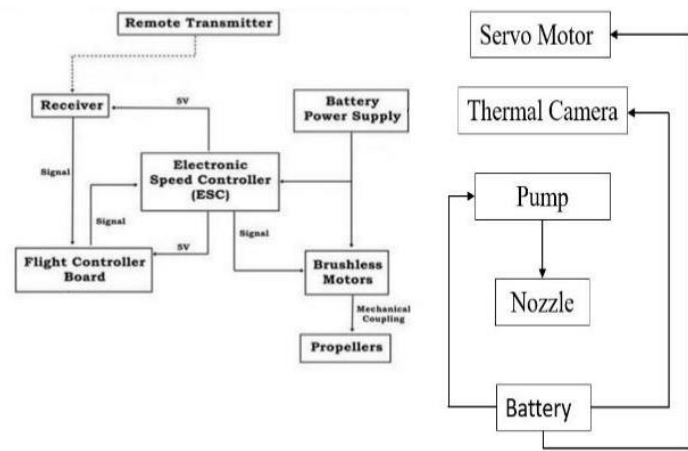

Fig 1. Fire Extinguishing Ball

\section{1) Motor}

\section{Components Used}

Outer runner BLDC motors in which there are no brushes, they have a permanent magnet. The RPM of the motor can be controlled by varying the input current. This motor U12 KV100 produces 4440 maximum Revolutions Per Minute (RPM) with 12s Li-Po battery and it produces a maximum thrust of 13392 grams with 30X10.5 inches propeller.

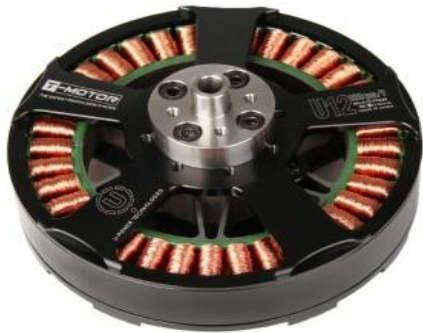

Fig 6. BLDC motor (T-motor KV 100)

2) Propeller

The propeller is of 30 inches length and has 10.5 inches pitch. It is made up of carbon fiber and Epoxy and it has less weight. These propellers also have High strength to weight ratio.

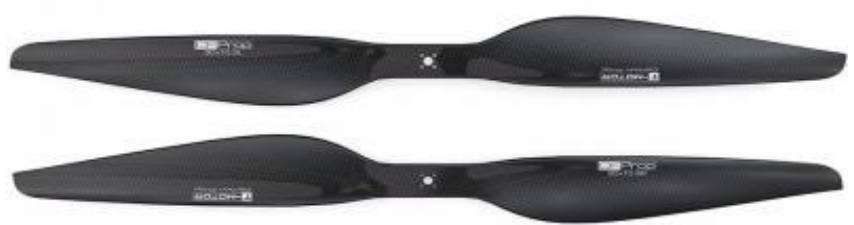

Fig 7. propeller (T-motor 30X10.5) 
3). $E S C$

It stands for Electronic Speed Controller and it is used to vary the RPM of the motor. $80 \mathrm{~A}$ rated ESC is used as per the motor and battery specifications.

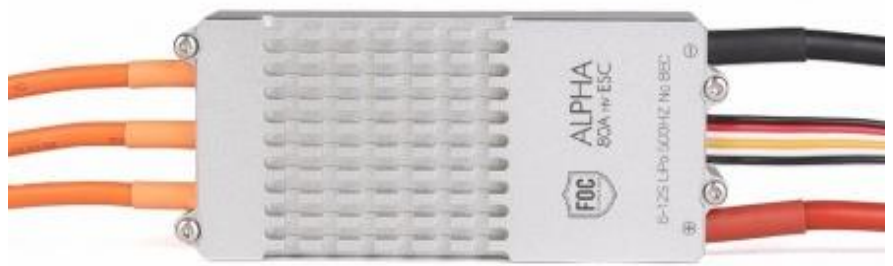

4) Battery

Fig 8. Alpha 80A ESC

The battery that can be used is a Li-Po battery of 16000 $\mathrm{mAh}$ current capacity, $44.4 \mathrm{~V}$ and $25 \mathrm{C}$ charge discharge Rate. In this battery twelve cells are connected in series $(12 \times 3.7=$ $44.4 \mathrm{~V})$

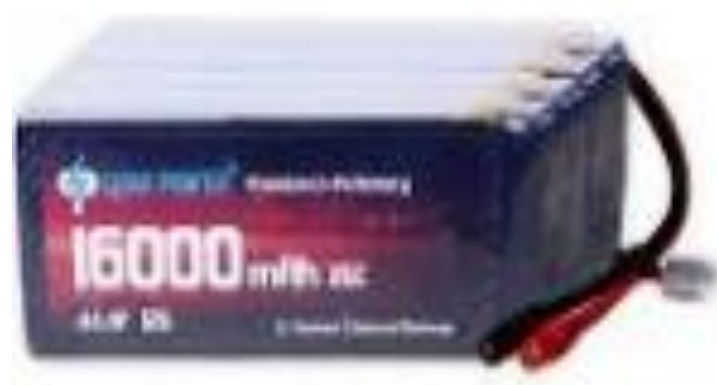

Fig 9. Li-Po battery to power motors

\section{5) Flight controller}

The flight controller helps in the maneuvering operations and also it provides Auto level function. The accelerometer and gyroscope sensors in the Flight controller processes the signals from the receiver and gives the output to the ESC. The Pixhawk 1 Flight controller can be used in the Drone, it also enables autopilot and the mission plan can be made using the software "Q Ground control Daily".

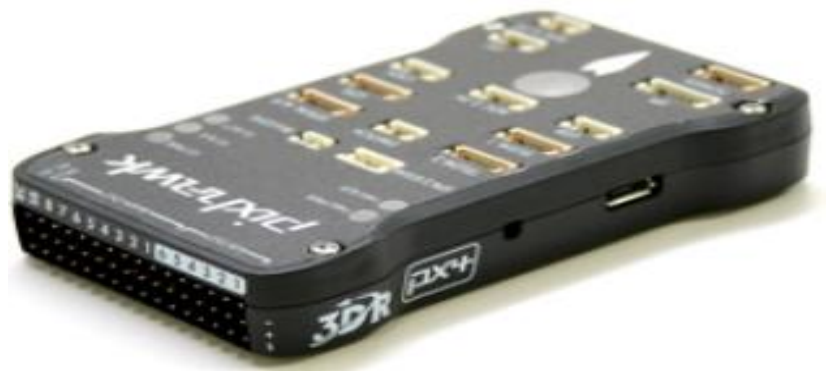

Fig 10. Pixhawk 1 Flight controller

\section{6) Radio Transmitter and Receiver}

The Transmitter and receiver used are FrSky Taranis X9D Plus Transmitter and X8R Receiver. This combination provides 3 times the range of current systems. This Transmitter and receiver provide upto 16 channel options.

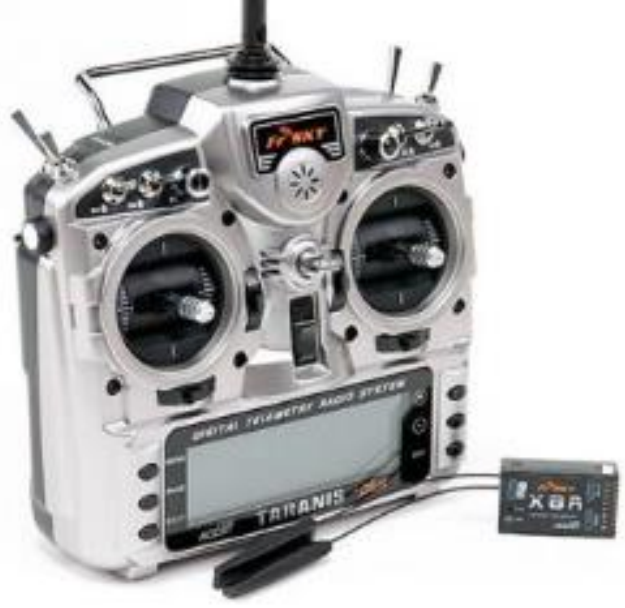

Fig 11. Fr sky Transis X9D transmitter and X8R Receiver

\section{E. Weight Build up}

TABLE I. Payload Data

\begin{tabular}{|c|c|}
\hline PARTS & WEIGHT IN (GRAMS) \\
\hline Motor (8No’s) & 6312 \\
\hline Propeller (8No's) & 2400 \\
\hline ESC (8No's) & 880 \\
\hline Main Frame & 3000 (approx.) \\
\hline Payload Frame & 2000 (approx.) \\
\hline Battery (2 NO’S) & 7620 \\
\hline Flight controller & 135 \\
\hline Other Fastening components & 500 (approx.) \\
\hline TOTAL & 22,767 (approx.) \\
\hline
\end{tabular}

The overall weight of the drone is calculated by adding the total weight of components and the weight of payload.

Overall weight $=$ Payload + Weight of components

$$
\begin{aligned}
& =10370+22767 \\
& =33,137 \text { grams(approx.) } \\
& \text { F. } \quad \text { Thrust Calculation }
\end{aligned}
$$

\section{F. Thrust Calculation}

The Thrust to Weight Ratio can be between 2.5 to 3.5, for this type of application, because the Drone has to carry more payload and it should also have better maneuverability.

Thrust produced by one propeller $\&$ one motor $=13392$ grams Total thrust produced at $100 \% \mathrm{RPM}=8 \times 13392$

$$
=107136 \text { grams }
$$

Thrust to weight Ratio $=$ Thrust produced $/$ total weight of drone

$$
\begin{aligned}
& =107136 / 33137 \\
& =3.23: 1
\end{aligned}
$$

Since the Thrust to Weight Ratio is 3.23 , the Drone will have better maneuverability and it can also be loaded with additional load about $10 \mathrm{Kg}$, then the Thrust to Weight Ratio will become $2.5: 1$ which will also contribute to good maneuverability. 


\section{G. Battery Drain Time Calculation}

Two Batteries are used separately to supply power only for the 8 motors.

Current Output from each battery $=16,000 \mathrm{mAh}$

Current consumption of each motor at $100 \% \mathrm{RPM}=34 \mathrm{~A}$

Current consumption of 4 motor at 100\% RPM $=136 \mathrm{~A}$

Battery Endurance $=$ Current output from battery/current consumption of 4 motor at $100 \%$ RPM

$$
\begin{aligned}
& =16000 \mathrm{mAh} / 136 \mathrm{~A} \\
& =16 * 60 / 136 \mathrm{~A} \\
& =7 \text { minutes (at } 100 \% \mathrm{RPM})
\end{aligned}
$$

The other battery which also provides power to the 4 motors will also have the similar endurance of 7 minutes (at $100 \%$ RPM).

Since the payload weight can be increased to $10 \mathrm{KGs}$, additionally two batteries can be added such that each battery powers 2 motors. In this case the Endurance will be around 14 minutes (at $100 \%$ RPM).

\section{STRUCTURAL DESCRIPTION}

The model of the Drone is designed in Catia V5 software. The Arm length is determined based on some of the factors like the Propeller dimensions, Clearance between two rotating Propellers and the Clearance between the parts of the drone from rotating propellers. The Main Frame is designed $\mathrm{H}-$ shaped to have more space between the arms. When the payloads are mounted on the Main Frame, then there will be change abruptly in the Center of Gravity, when the Fire Extinguisher balls are dropped or the Water storage tank gets drained. So, to avoid this problem, another frame is designed to mount payloads. The shell designed to hold the Fire Extinguisher ball will have a slope bottom instead of the flat, so that the ball will be released easily.

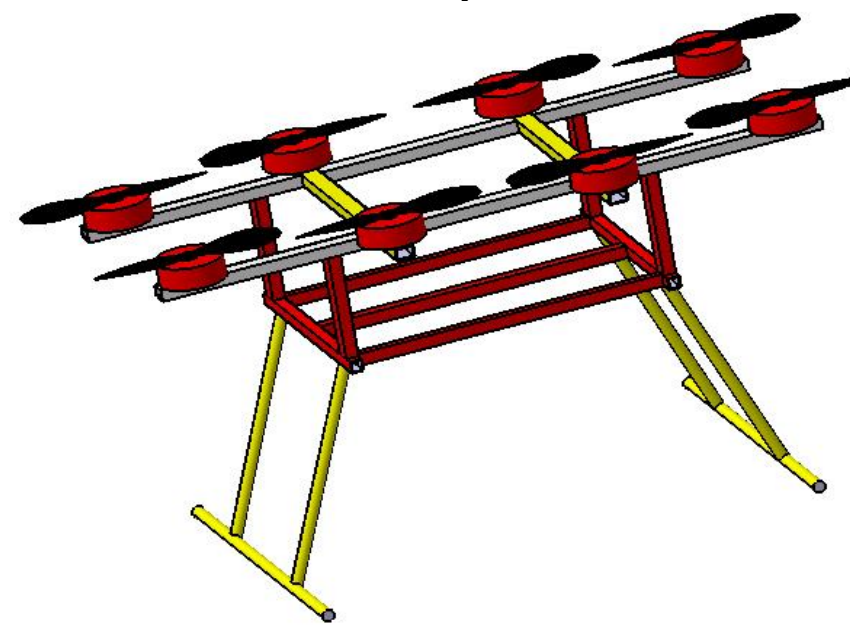

Fig 12. CAD model of the Drone

\section{CONCLUSION}

This paper describes the importance of the Drone in Firefighting Operation. The Drone has designed in such a way that carries a maximum of $20 \mathrm{Kg}$ payload with 14 minutes battery Endurance. It reduces the risk to the personnel involved in Firefighting operations. This Drone with Thermal Imaging camera can also be used to detect the people who were trapped in the buildings during Fire accident.The drones need to become smart and quick-witted in order to optimize industrial processes, maximum their utility and can be widely established in the future factories.If more emphasis is laid upon these criteria, they can be pertained in Engineering, maintenance,critical infrastructure management and asset management operations.Implementation of Drone systems in were trapped in the buildings during Fire accident. The drones need to become smart and quick-witted in order to optimize industrial processes, maximize their utility and can be widely established in future factories. If more emphasis is laid upon these criteria, they can be pertained in engineering, maintenance, critical infrastructure management and asset management operations. Implementation of drone systems in the industry can boast new opportunities and new innovative business models. There are nearly 35 drone Start-Up companies in India and they are trying to impose these innovative technologies into their systems to make their processes safer, more reliable and more predictable. From the industrial point of view, implementation of this technology can be ideal in the automotive industry.

\section{REFERENCES}

[1] Burchan Aydin, Emre Selvi, Jian Tao and Michael J. Starek, "Use of Fire-Fighting Balls for a Conceptual System of Drone-Assisted Wildfire Fighting" MDPI, March 2019, doi:10.3390/drones3010017.

2] Abdulla Al-Kaff, Angel Madridano, Sergio Campos, Fernando Garcia, David Martin and Arturo de la Escalera, "Emergency Support Unmanned Aerial Vehicle Forest Fire Surveillance” MDPI, Sept 2019, doi10.3390/electronics9020260.

[3] Manuj C., Adarsh M Rao, Rahul S, Suhas C N, Vismay K G, "Design and Development of Semi-Autonomous fire Fighting Drone" Journal of Mechanical and Civil Engineering (IOSR-JMCE) June 2019, e-ISSN: 2394-3343.

[4] Abinesh D. V, Deepak A. K, Chandraprakash K.Gowtham.M,Ananth .I," Fire Fighting Drone” IJIERE 2017, Volume 4, e-ISSN: 2394-3343.

[5] Dr. Ronald T. Wakeham \& Dr. John C. Griffith, "Unmanned Aerial Systems in the Fire Service: Concepts and Issues.” JMER,June 2018, eISSN: $2536-8$ 